\title{
ANALYSING LONGITUDINAL TURBULENCE INTENSITY IN VEGETATED CHANNELS
}

\author{
Francesco Giuseppe Carollo, Vito Ferro, Donatella Termini
}

\section{Introduction}

The structure of flow turbulence plays a dominant role in many phenomena such as diffusion, erosion, sediment transport, and energy dissipation. Vegetation affects the flow velocity and the turbulence structure in channels. However, altering the hydrodynamic conditions influences the exchanges of sediment [30], nutrients [3] and other contaminants [8, 24]. Furthermore, additional drag exerted by vegetation reduces suspended sediment transport capacity of open channel flow, when compared to non-vegetated similar conditions [21], and alters floodplain conveyance. Dealing with environmental flows motivated the need for a better understanding of the turbulence structure and its associated transport mechanisms. The focus of this paper is to enhance out understanding of how vegetation impacts on vertical distribution of turbulence intensity using experiments in an open-channel flume with submerged flexible vegetation.

Many theoretical and experimental investigations have been performed in order to analyze both the mean flow and turbulence structure of open-channel flow [20, 27, 32]. For examining the turbulence structure of open-channel flow, the near wall region (inner region) is distinguished from the outer one [13, 28]. In the inner region, defined by $y / h<0.15-0.20$ or the scaled distance $y^{+}=y u^{*} / v<100$ [5] being $y$ the distance from the channel bed, $h$ the flow depth, $u^{*}$ the shear velocity and $v$ the kinematic viscosity, the turbulent structure is controlled by the inner variables (kinematic viscosity and shear velocity). In the outer

Paper received 26.01.2007; accepted 06.12.2007

Ing. Francesco Giuseppe Carollo, Ph.D, Dipartimento di Ingegneria e Tecnologie Agro-Forestali, Sezione Idraulica, Facoltà di Agraria, Università di Palermo, Viale delle Scienze, 90128 Palermo.

Prof. Vito Ferro, Ordinario di "Idraulica Agraria e Sistemazioni Idraulico-Forestali", Dipartimento di Ingegneria e Tecnologie AgroForestali, Sezione Idraulica, Facoltà di Agraria, Università di Palermo, Viale delle Scienze, 90128 Palermo, vferro@unipa.it.

Prof. Donatella Termini, Dipartimento di Idraulica ed Applicazioni Ambientali, Facoltà di Ingegneria, Università di Palermo, Viale delle Scienze, 90128 Palermo. region the viscous effects on the turbulent structure are negligible. In this region, strongly influenced by the free surface, Smutek [33] showed a damping of vertical velocity fluctuations and, thus, a reduction in eddy viscosity.

Using experimental observations both in smooth and in rough beds [23, 26, 27], many attempts have been made to analytically describe the structure of turbulence in open-channels flows.

In smooth-bed channels, the Nezu's exponential law [26] is usually used to describe the vertical distribution of the longitudinal turbulence intensity $u$ ' normalized with the shear velocity:

$$
\frac{u^{\prime}}{u^{*}}=D \exp (-\lambda Y)
$$

in which $D$ and $\lambda$ are empirical constants to be estimated by measured data and $Y=y / h$ is the relative water depth.

Equation (1) is theoretically deduced for $50<y^{+}<0.6 h u^{*} / v$, in which the equilibrium between the energy of turbulence generation and its dissipation exists [28]. Nezu and Rodi [27] measured in detail the distribution of turbulent intensity for the flow in a smooth-bed flume with a two-dimensional LDA. By regression analysis on their experimental results and some data obtained by Clark [7], Blinco and Partheniades [4], Nezu [26], and Steffler et al. [34], Nezu and Rodi [27] obtained $D=2.26$ and $\lambda=0.88$ that are nearly the same as the values $D=2.3$ and $\lambda=1.0$ by Nezu [26].

Near the bed (i.e. for $\left.y^{+}<50\right)$ the influence of viscosity cannot be neglected and the description of turbulence characteristics of the flow is more complex because of both the absence of equilibrium between the energy of turbulence generation and its dissipation and the existing of bursting phenomena.

Experimental runs carried out in laboratory flume having a rough bed $[1,2,11,14,22,31]$ showed that bed roughness affects the vertical distribution of longitudinal turbulence intensity, especially near the wall. Comparing the experimental results obtained in a laboratory flume both with smooth-bed and rough- 
bed, Grass [11] established that the peak value of the normalized turbulence intensity gradually decreases for increasing values of the shear Reynolds number $k_{s}^{+}=k_{s} u^{*} / v$, where $k_{s}$ is the equivalent bed roughness. In fact, increasing of bed roughness produces a reduction of the macroscale turbulence due to damping of large-scale eddies [11, 26, 27]. Far from the wall, the effect of the roughness becomes fairly weak or negligible. Significantly, previous papers [28] show that roughness has no influence on turbulence intensity for relative water depth $Y$ larger than 0.3 , where the quasi-theoretical relationship (1) can be applied. Near the wall, i.e. for $Y<0.3$, the roughness effect is clearly appreciable.

Very few studies analyze the turbulence structure in vegetated channels and, presently, there are no models readily available for predicting the distribution of turbulence intensities.

Experimental runs carried out in a laboratory flume with flexible bottom vegetation [12, 18], investigated some peculiar characteristics of flow turbulence structure. The measurements carried out by Ikeda and Kanazawa [12] using artificial filaments on the flume bed, revealed the generation of periodic organized vortices whose center is located slightly above the top of the vegetation layer. The intermittent motion of these coherent structures has been strongly correlated to the flexible vegetation oscillation, known as the monami [9]. The form of the vortex was elliptical with the long axis inclined downwards toward the front. Moreover, many experimental runs carried out using bent vegetation $[6,10,16,35]$ showed that the velocity profile in a vegetated channel is characterized by an inflection point occurring at the top of the bent vegetation. Here, the flow becomes unstable, rolling up into discrete vortices and the turbulence intensity reaches the highest value. Ghisalberti and Nepf [9] noticed that the flow structure within and just above the canopy is close to a mixing layer characterized by two regions of constant velocity separated by a confined region of shear containing an inflection point. According to these Authors the flow is susceptible to Kelvin-Helmholtz instabilities leading to the generation of large, coherent vortices within the mixing layer.

Recently, Carollo et al. [6] analyzed the velocity profile in a vegetated-bed laboratory flume and identified three characteristics zones, marked by two relative water depths $Y_{1}$ and $Y_{2}$ (Figure 1):

1. zone I $\left(Y<Y_{1}\right)$, inside the bent vegetation layer, characterized by very small velocities and increasing vertical velocity gradient;

2. zone II $\left(Y_{1}<Y<Y_{2}\right)$ where flow velocity rapidly increases with $Y$ and the velocity distribution is logarithmic-type;

3. zone III $\left(Y>Y_{2}\right)$ characterized by positive vertical velocity gradients which are progressively decreasing until to become zero near the free surface, where the velocity reaches a constant value equal to the maximum one.

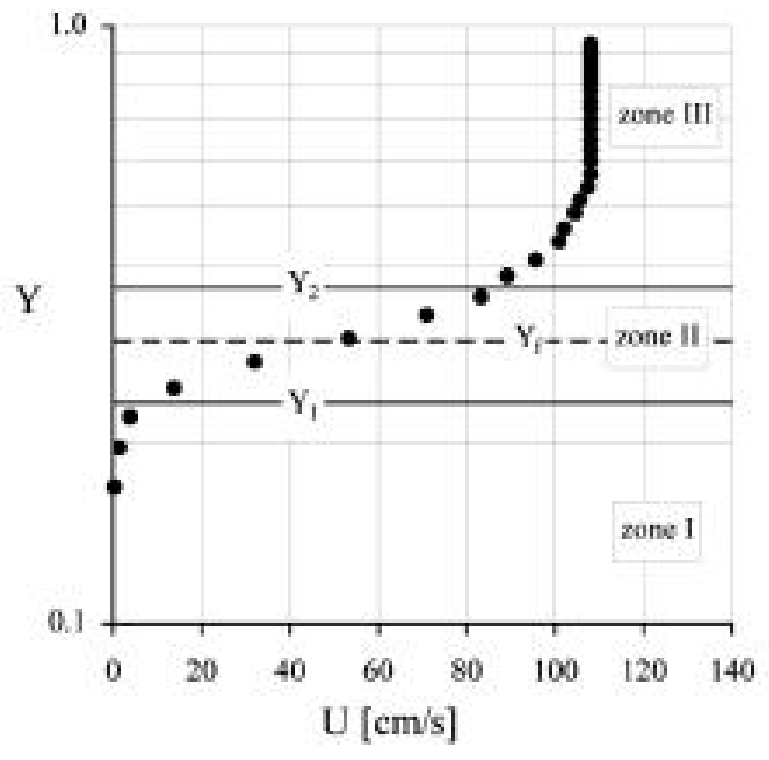

Fig. 1 - Example of velocity profile in a vegetated channel.

Inside zone II, even if logarithmic velocity profile can be fitted, an inflection point of the velocity profile clearly occurs at a distance from the bed equal to the submerged bent vegetation height $k_{v}$. Therefore, at this height the velocity gradient reaches the maximum value. The joined analysis of experimental velocity profiles and corresponding turbulence intensity distributions [6] showed that the inflection point of the velocity profile occurs at a relative depth $Y_{f}$ equal to the relative depth $Y_{t}$ where the maximum turbulence intensity occurs.

In this paper, results of turbulence intensity measurements carried out in a vegetated laboratory flume by using a 2D-Acoustic Doppler velocimeter are initially examined. Then an exponential distribution, similar to Nezu's law, is fitted to the measured turbulence intensity profiles. Finally a new relative turbulence intensity distribution is proposed.

\section{Experimental installation and measurement technique}

The experimental runs were carried out in a rectangular straight laboratory channel of Dipartimento di Ingegneria Idraulica ed Applicazioni Ambientali at the University of Palermo. The flume has a sloping bed and is $0.60 \mathrm{~m}$ wide and $14,4 \mathrm{~m}$ long (Figure 2). The measurement reach, located at $7.9 \mathrm{~m}$ from the entrance channel section, was $3 \mathrm{~m}$ long. The turf layer was produced sowing a soil layer having a thickness of $5 \mathrm{~cm}$, and then the obtained vegetated plot was installed into the measuring reach. The grass bed was a mixture of stable Lolium (50\%), Festuca rubra (40\%) and Poa pratensis (10\%). The obtained vegetation was ribbon-like characterized by a width of about 0.5 $\mathrm{cm}$. The experimental runs were carried out for three values of the vegetation concentration, $\delta(280,377$, 
440 stems $/ \mathrm{dm}^{2}$ ). The number of stems per unit area (concentration) was measured in a reference area 0.6 $\mathrm{m}$ wide and $1.0 \mathrm{~m}$ long. In each reference area five hollow steel cylinders (internal diameter $4.4 \mathrm{~cm}$ ) were inserted into the soil layer to extract cores of sod, and the number of stems in each sample were counted. The concentration $\delta$ was set equal to the mean value of the five measurements. The bent vegetation height, $k_{v}$, (i.e. the vegetation heigth in presence of flow) and non-submerged vegetation height (i.e. the vegetation heigth in absence of flow), $H_{v}$, were estimated as the mean of three measurements by three decimal rules fixed to flume wall. The frontal area index (f.a.i.), estimated as product of $\delta, H_{v}$ and of the stem width, ranges between 5.9 and 44.0 .

The turf layer was jointed with the flume bed by two plane chutes $(50 \mathrm{~cm}$ long and $5 \mathrm{~cm}$ height) that bounded the experimental reach. The reference level was set coincident with the upper soil surface where the plants were rooted, at $5 \mathrm{~cm}$ above the flume bed. The water depth was measured by an hydrometer in four cross-sections: the first was at $90 \mathrm{~cm}$ downstream from the beginning of turf reach and the following three cross-sections had a relative distance of $40 \mathrm{~cm}$. The maximum difference between the water depth $h_{\mathrm{i}}$ in the i-th cross-section and the mean value $h$, was obtained for the first and the last cross-section. In these cross-sections the water depth $h_{\mathrm{i}}$ was, on average, $\pm 7 \%$ from the value of $h$. In the other cross-section, instead, the water depths $h_{\mathrm{i}}$ were close to the mean value $h(0.99-1.02 \mathrm{~h})$. These circumstances suggest that in the middle part of experimental reach quasiuniform flow conditions occurred.

The experimental runs were carried out varying, for each stem concentration, the flow rate $Q$ and the flume bed slope $s$. The hydraulic conditions used for each of fifteen runs are listed in table 1. For each run, table 1 also lists the frontal area index, f.a.i., and the minimum and maximum values of the momentum thickness, $\theta$, calculated as suggested by Ghisalberti and Nepf [9]. For all runs, the vegetation was submerged. Runs 1-13 were carried out with a vegetation which was always prone; while for runs 14 and $15\left(H_{v}\right.$ $=5.9$ and $3.5 \mathrm{~cm}$ ) the vegetation was cut (original vegetation height equal to $10 \mathrm{~cm}$ ) for obtaining more rigid stems having a quasi-erect configuration.

The local flow velocities were measured by using a 2D, side-looking probe, Acoustic Doppler Velocimeter (ADV) [17] in five verticals (noted with v1, v2, $\mathrm{v} 3, \mathrm{v} 4$ and va) of a cross-section located in the middle of the measuring reach. The measurements positions were located at a distance of the wall equal to $4 \mathrm{~cm}$ (v1), $7 \mathrm{~cm}$ (v2), $14 \mathrm{~cm}$ (v3), $22 \mathrm{~cm}$ (v4) and $30 \mathrm{~cm}$ (axial vertical, va).

The 2D-ADV acoustic sensor was connected to a signal conditioning module. It was mounted on a rigid stem $40 \mathrm{~cm}$ long and was composed of one transmitting transducer and two receiving transducers. The

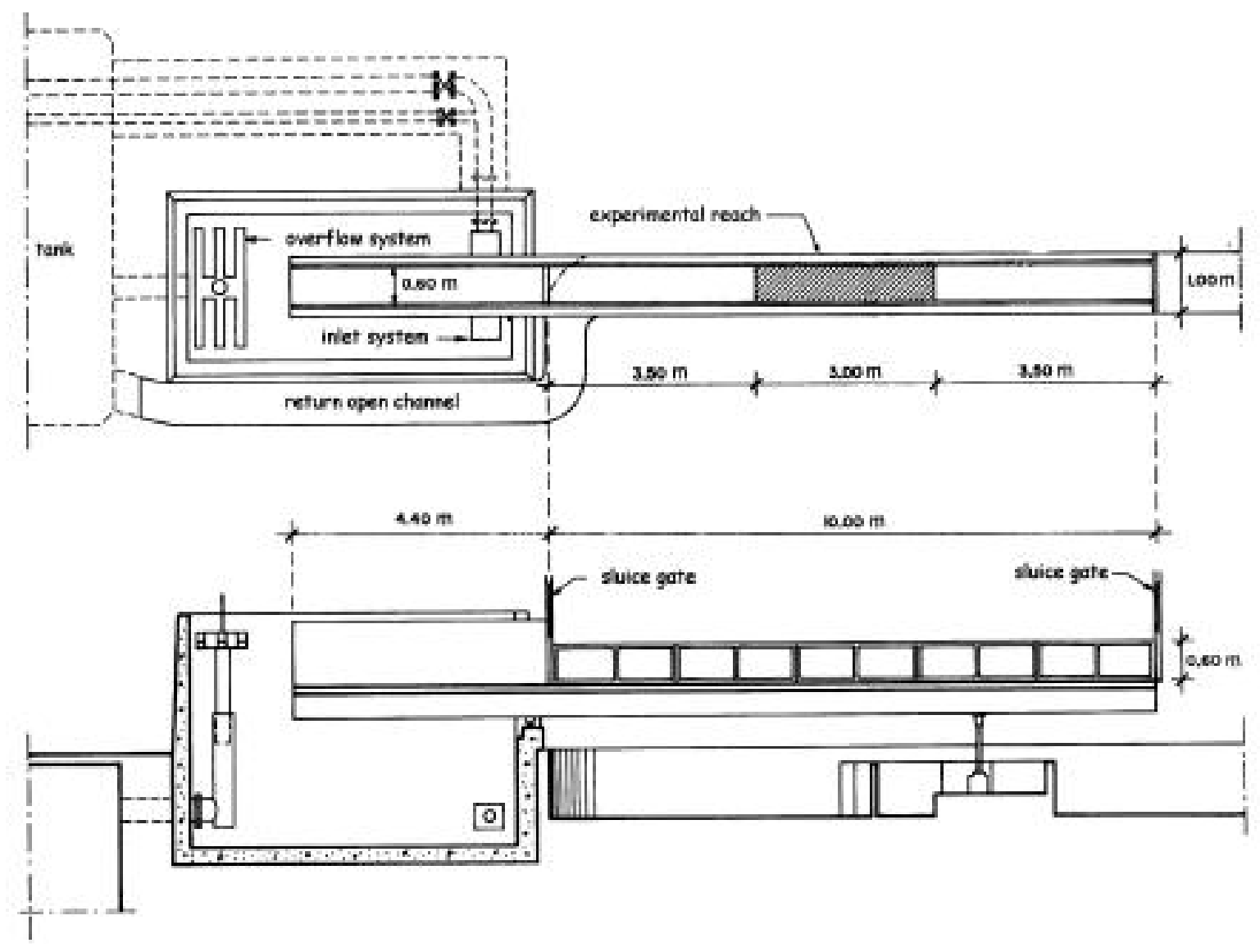

Fig. 2 - Lay-out of the experimental installation. 


\begin{tabular}{cccccccccc}
\hline Run & $h$ & $s$ & $Q$ & $H_{v}$ & $\delta$ & $k_{v}$ & $f . a . i$. & $\theta$ & $u^{*}$ \\
& {$[\mathrm{~cm}]$} & {$[\%]$} & {$[1 / \mathrm{s}]$} & {$[\mathrm{cm}]$} & {$\left[\mathrm{st.dm}^{-2}\right]$} & {$[\mathrm{cm}]$} & & $\begin{array}{c}\text { min-max } \\
{[\mathrm{cm}]}\end{array}$ & $\begin{array}{c}\text { min-max } \\
{[\mathrm{cm}]}\end{array}$ \\
\hline 1 & 13.5 & 1.0 & 30.1 & 20.0 & 440 & 8.0 & 44.0 & $0.22-0.38$ & $5.2-14.8$ \\
2 & 14.6 & 0.2 & 30.1 & 20.0 & 440 & 8.0 & 44.0 & $0.16-0.37$ & $2.7-7.2$ \\
3 & 14 & 0.2 & 26.9 & 20.0 & 440 & 8.2 & 44.0 & $0.22-0.5$ & $2.2-5.4$ \\
4 & 12.5 & 1.0 & 26.9 & 20.0 & 440 & 7.7 & 44.0 & $0.21-0.46$ & $5.3-11.8$ \\
5 & 17.8 & 0.2 & 77.6 & 20.0 & 440 & 7.0 & 44.0 & $0.21-0.61$ & $2.6-6.8$ \\
6 & 16.8 & 1.0 & 77.6 & 20.0 & 440 & 6.6 & 44.0 & $0.21-0.53$ & $6.8-16.8$ \\
7 & 19.9 & 0.2 & 105.9 & 20.0 & 440 & 6.3 & 44.0 & $0.34-0.79$ & $4.1-7.1$ \\
8 & 18.3 & 1.0 & 105.9 & 20.0 & 440 & 5.9 & 44.0 & $0.17-0.71$ & $4.6-11.2$ \\
9 & 12.8 & 0.2 & 26.9 & 11.5 & 280 & 7.0 & 16.1 & $0.32-0.71$ & $1.7-3.6$ \\
10 & 19 & 0.2 & 77.6 & 11.5 & 280 & 5.4 & 16.1 & $0.72-1.15$ & $3.2-8.2$ \\
11 & 21.7 & 0.2 & 105.9 & 11.5 & 280 & 4.9 & 16.1 & $0.6-1.24$ & $2.7-5.4$ \\
12 & 24.5 & 0.2 & 135.0 & 11.5 & 280 & 4.7 & 16.1 & $0.68-1.39$ & $4.9-8.3$ \\
13 & 27.2 & 0.2 & 170.8 & 11.5 & 280 & 4.5 & 16.1 & $0.27-1.29$ & $2.6-5.8$ \\
14 & 27.7 & 0.2 & 188.7 & 5.9 & 337 & 3.8 & 9.9 & $0.79-1.29$ & $3.2-5.5$ \\
15 & 27.2 & 0.2 & 189.2 & 3.5 & 337 & 3.1 & 5.9 & $0.99-1.48$ & $7.7-11.9$ \\
\hline
\end{tabular}

TABLE 1 - Hydraulic and vegetation data of the experimental runs.

three transducers were in the same plane and aligned along the $x$ axis set coincident with the main flow direction. The intersection of the receiving and the transmitting beams defined the barycentre of the sampling volume $\left(0.25 \mathrm{~cm}^{3}\right)$ localized at $5 \mathrm{~cm}$ from the axis of the acoustic sensor along the transverse direction ( $t$ direction). Only the ADV measurements characterized by a signal to noise ratio (SNR) greater than $20 \mathrm{~dB}$ were collected; this adopted SNR value is greater then the one $(15 \mathrm{~dB})$ suggested in the ADV Operation Manual [29] by Nortek-as. According to Wahl [36] SNR values must be greater than $5 \mathrm{~dB}$ for mean flow velocity measurements and greater than 15 $\mathrm{dB}$ for measurements of instantaneous velocity or tur-

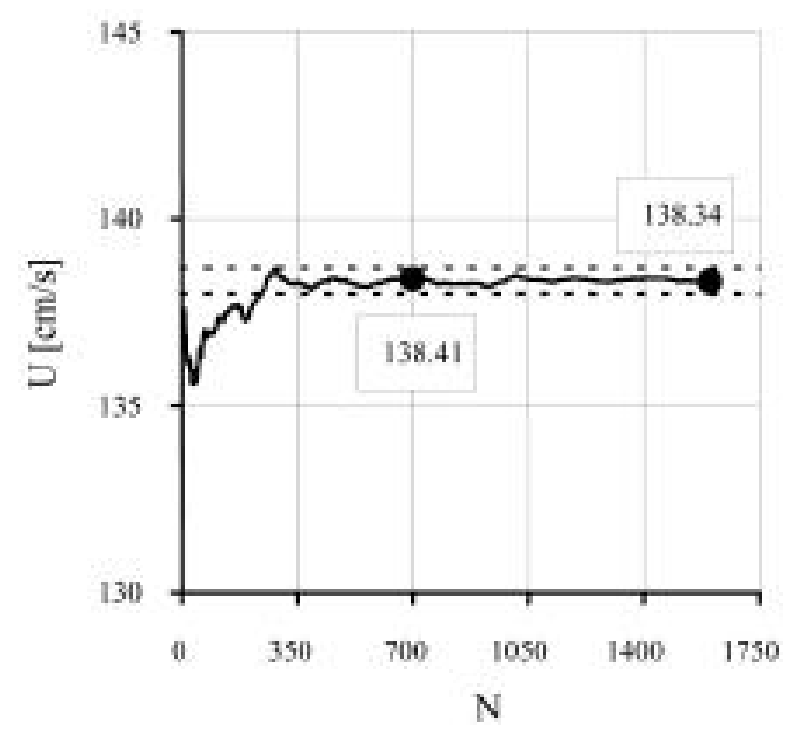

Fig. 3 - Variation of the local mean longitudinal flow velocity with the number of samplings. bulence quantities. For this measurement condition the accuracy is better than $\pm 0,25 \%$ or $\pm 0,25 \mathrm{~cm} / \mathrm{s}$, whichever is greater [17].

For each measurement point the maximum sampling rate of $25 \mathrm{~Hz}$ was used. The number $N$ of samplings was set equal to the minimum value required to determine a constant local mean velocity $U$. The tests carried out for different values of $\delta, h$ and $y$ showed that 700 local velocity samplings are sufficient to obtain a stable estimate of $U$ (Figure 3).

For each measurement point, the turbulence intensity $u$ ' was calculated by the following relationship:

$$
u^{\prime}=\sqrt{\frac{\sum_{\mathrm{i}=1}^{N}\left(u_{\mathrm{i}}-U\right)^{2}}{N}},
$$

in which $u_{\mathrm{i}}$ is the local instantaneous longitudinal flow velocity.

Figure 4 shows that the turbulence intensity distribution obtained using 1600 samplings coincides with the one measured by 700 samplings.

\section{Analysing turbulence intensity experimental distributions}

For plotting the experimental normalized turbulence intensity distributions $\left(u^{\prime} / u^{*}\right.$ versus $\left.Y\right)$, the shear velocity $u^{*}$ was calculated by the Clauser method [14]. In particular, the velocity distribution over natural and artificial flexible roughness was be represented by the following logarithimic-type equation [10, $16,25]$ :

$$
U=b_{0}+b_{1} \ln y
$$

in which $b_{0}$ and $b_{1}$ are coefficients to be estimated by velocity measurements.

Taking into account that inside zone II a logarithmic velocity profile can be fitted to measured veloci-

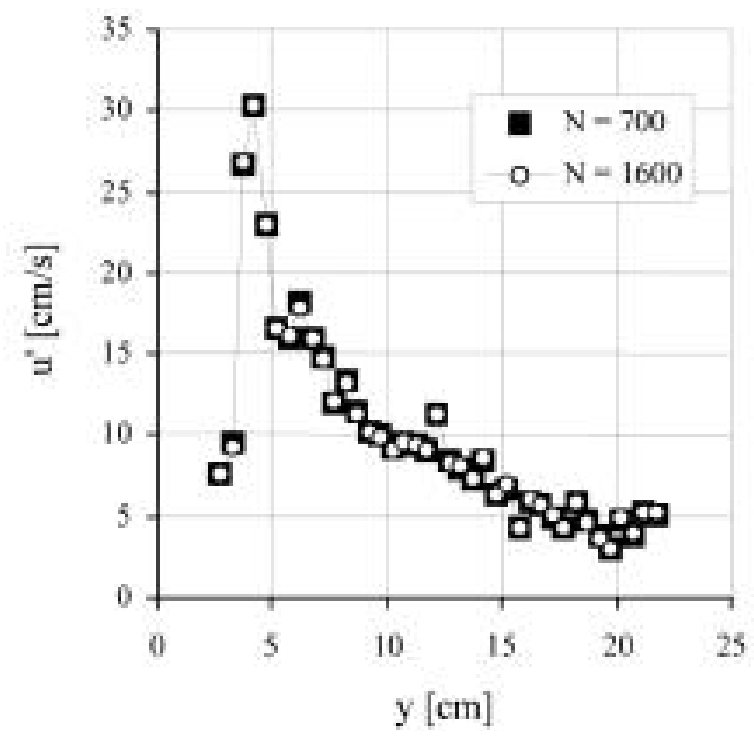

Fig. 4 - Measured turbulence profiles characterized by a different number of samplings. 
ties [6], for each measured profile the coefficients $b_{0}$ and $b_{1}$ of eq. (3) were estimated by the least squares method. Deriving eq. (3) and applying the Prandtl von Karman theory, the following relationship is deduced:

$$
u^{*}=k b_{1}
$$

in which $k$ is the von Karman's constant set equal to 0.4 . For each run, Table 1 also lists the minimum and maximum values of $u^{*}$ calculated with eq. (4).

Figure 5 shows the comparison between a measured turbulence intensity distribution and the corresponding vertical velocity profile. Some peculiar characteristics of the vertical profile of turbulence intensity, which agree with results of previous studies [12], are highlighted in this figure: 1) the turbulence intensity profile shows a peak value at a relative water depth $Y_{t}$ corresponding to the relative depth $Y_{f}$ of the inflection point of the velocity distribution; 2) for $Y<Y$ the turbulence intensity increases rapidly; 3) for $Y>Y$ the turbulence intensity decreases until $Y=Y_{\max }$, being $Y_{\max }$ the relative water depth in which the maximum value of velocity is reached; then, i.e. for $Y>Y_{\max }$, the turbulence intensity assumes a constant low value.

The normalized turbulence intensity distribution shows a trend similar to that observed in non-vegetated bed channels [11], especially in the range $Y_{t}<Y<Y_{\text {max }}$. Approaching the free surface the decrease in vertical velocity gradient coincides with the decrease in turbulence intensity. Furthermore when the vertical velocity gradient is close to zero the turbulence intensity becomes constant. For $Y<Y_{t}$ the turbulence intensity increases with $Y$, as well as the vertical velocity gradient.

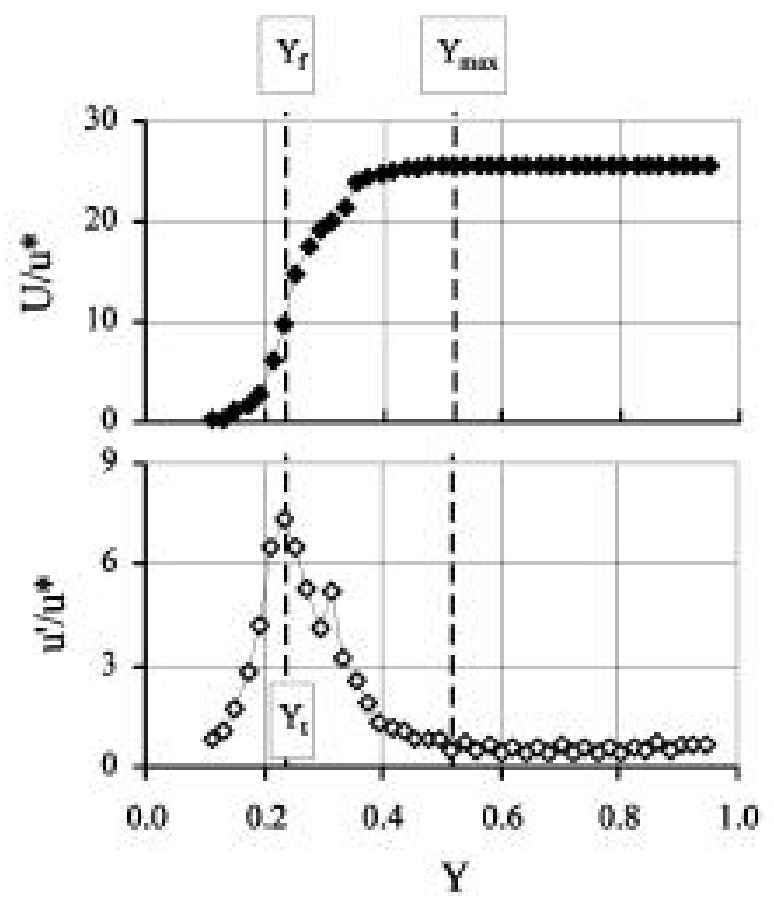

Fig. 5 - Comparison between a measured turbulence intensity distribution and the corresponding velocity profile.
During the experiments a strong oscillation of stems was observed. The vegetation stems were bent with different inflection degrees and oscillated in the flow changing position and producing a variation of the bent vegetation height. According to Ikeda and Kanazawa [12], the motion of the flexible vegetation is strongly related to the high velocity gradient and to the inflection of the velocity profile occurring at the top of vegetation layer [6]. The flow instability causes a vortex generation and the generated vortices move downstream just above the vegetated layer producing the wavy motion of the flexible stems, known as monami [9].

The cyclic presence and absence of vegetation stems in the region where monami appears determines a strong variability on instantaneous longitudinal velocities. This variability produces a peak value of the normalized turbulence intensity $u_{\max }^{\prime} u^{*}$, as eq. (2) establishes. Therefore, the peak value of $u_{\text {max }} / u^{*}$ appears at the same distance from the bed where the number of changes (presence - absence of vegetation stems) is maximum.

These observations and the results of a previous work [6] support the idea that the relative water depth $Y_{t}$, where the peak of turbulence intensity occurs, can be considered as a local estimate of the relative distance of the top of the bent vegetation layer from the bed.

The measured peak value of the turbulence intensity $u_{\text {max }} / u^{*}$ is higher than the one observed $\left(u_{\text {max }} / u^{*}\right.$ $<3.6)$ in non-vegetated beds [4, 28, 37].

For a given vegetation concentration $(\delta=280$ stems $\left./ \mathrm{dm}^{2}\right)$, Figure 6 shows that, the relative vegetation roughness $\left(k_{y} / h\right)$, strongly affects the turbulence intensity distribution. Taking into account that the relative depth $Y_{t}$ increases with the relative roughness, the whole turbulence intensity profile is shifted toward the free surface.

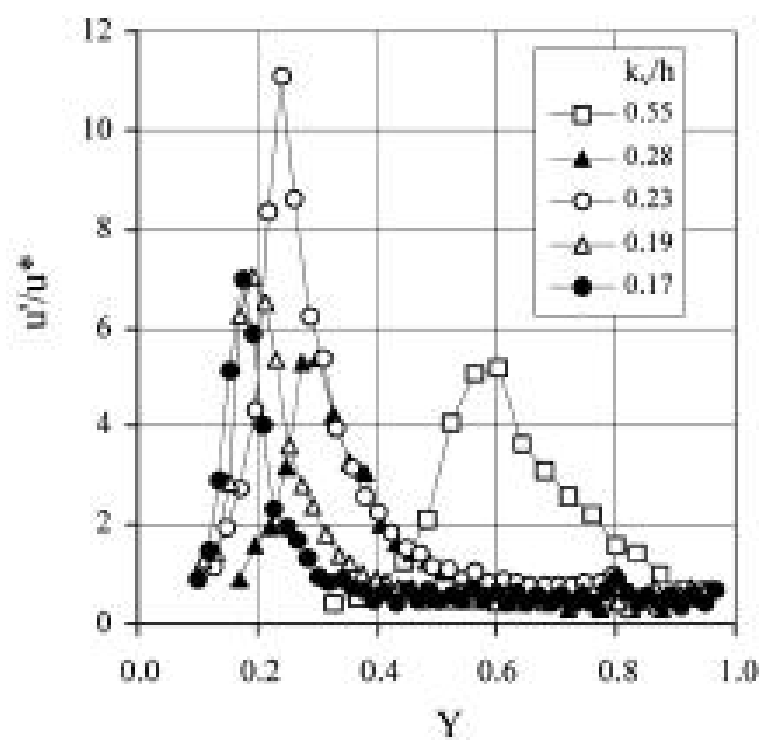

Fig. 6 - Turbulence intensity distributions measured in the axial vertical and corresponding to different values of the relative roughness. 


\section{Turbulence intensity profile}

\subsection{Exponential distribution}

Figure 5 clearly reports that in the region upon the vegetation layer and below the region where velocity is constantly equal to its maximum value $\left(Y_{t} \leq Y\right.$ $<Y_{\max }$ ) the normalized turbulence intensity profiles show a decreasing trend, similar to those observed in non-vegetated beds. This trend can be described by the following exponential law, similar to eq. (1):

$$
\frac{u^{\prime}}{u^{*}}=D^{\prime} \mathrm{e}^{-\lambda^{\prime} z}
$$

in which $D^{\prime}, \lambda^{\prime}$ are empirical constants that have to be estimated using turbulence intensity measurements and $Z$ is the following normalized variable:

$$
Z=\frac{Y-Y_{t}}{Y_{\max }-Y_{t}},
$$

which gives $Z=1$ for $Y=Y_{\max }$ and $Z=0$ for $Y=Y_{t}$.

The normalized variable $Z$ allows to take into account the effect of the spatial variability of $Y_{\mathrm{t}}$ on the turbulence intensity distribution.

As an example for $\delta=280 \mathrm{stems} / \mathrm{dm}^{2}$ and for axial measurement vertical, Figure 7 shows the experimental distributions corresponding to different relative roughness $k_{v} / h$ values. For a given relative roughness, Figure 7 shows that the equation (5) fits the experimental pairs quite well; varying the relative roughness the theoretical distribution transfer themselves almost in parallel, even if no apparent trend with the relative roughness is shown. Furthermore, no trend was observed with the distance of the measurement vertical from the wall. The turbulence intensity is probably more dependent on the local condition of vegetated bed than on the distance from the wall. In other

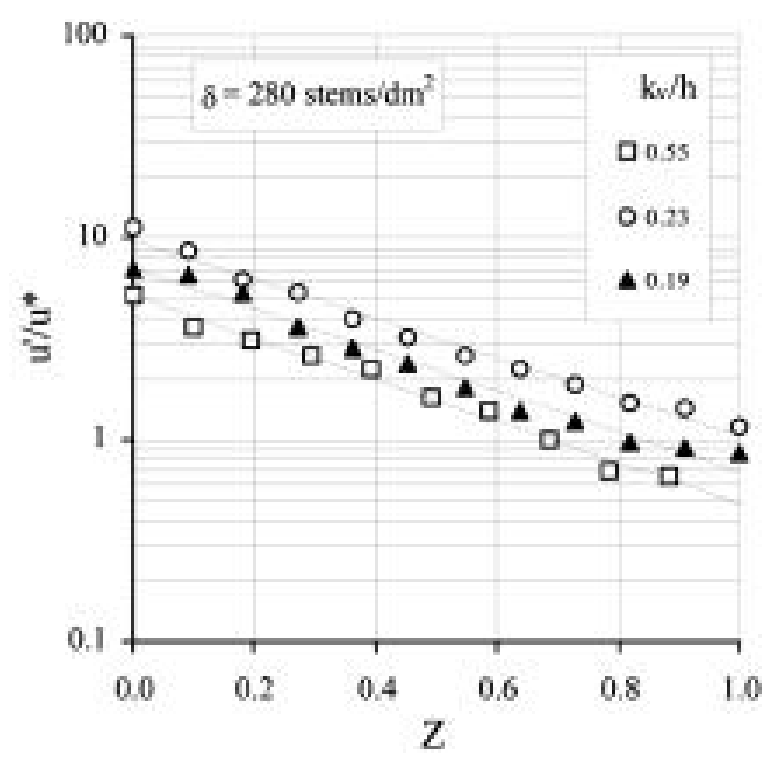

Fig. 7 - Fitting of eq. (5) to experimental turbulence intensity distributions characterized by different values of the relative roughness.

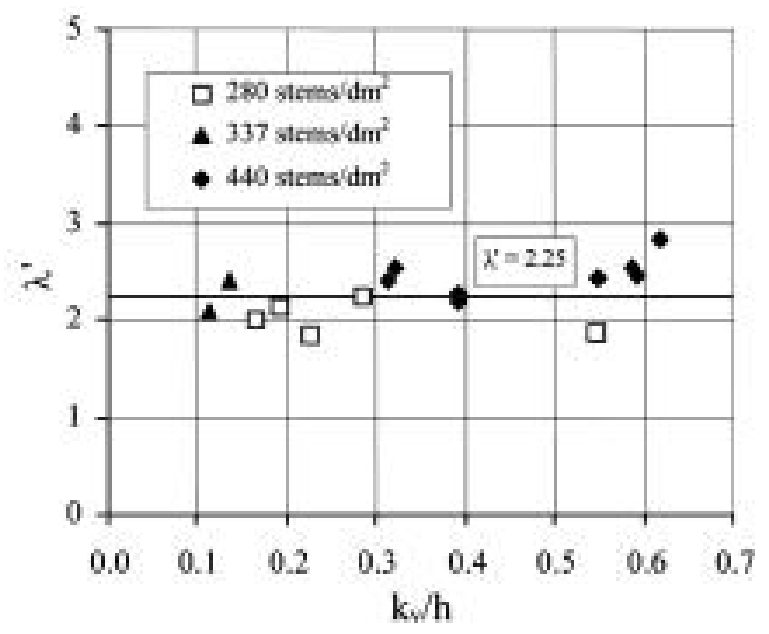

Fig. 8 - Values of $\lambda^{\prime}$ parameter corresponding to different stem concentration and relative roughness values.

words, the absence of trend with distance from the wall is due to the strong difference between the vegetated bed roughness and the glass wall roughness.

Neglecting the influence of the walls, equation (5) was fitted to all data pairs $\left(Z, u^{\prime} / u^{*}\right)$ surveyed in the five measurement verticals of the cross-section. (5)

Figure 8 shows that the parameter $\lambda^{\prime}$ has a low variability (standard deviation equal to 0,274 ) with both the relative vegetation roughness and the stem concentration.

For each stem concentration Figure 9 reports the relationship between the parameter $D^{\prime}$ and the relative roughness $k_{\mathrm{v}} / h$. The decreasing trend showed in Figure 9 seems related more to the increasing of stem concentration than to the increasing of relative roughness. In fact, for a given stem concentration, no characteristic trend may be observed in Figure 9.

For each stem concentration, using a constant value of $\lambda^{\prime}\left(\lambda^{\prime}=2.25\right)$, a single relationship (5) was fitted to all available data pairs $\left(Z, u^{\prime} / u^{*}\right)$.

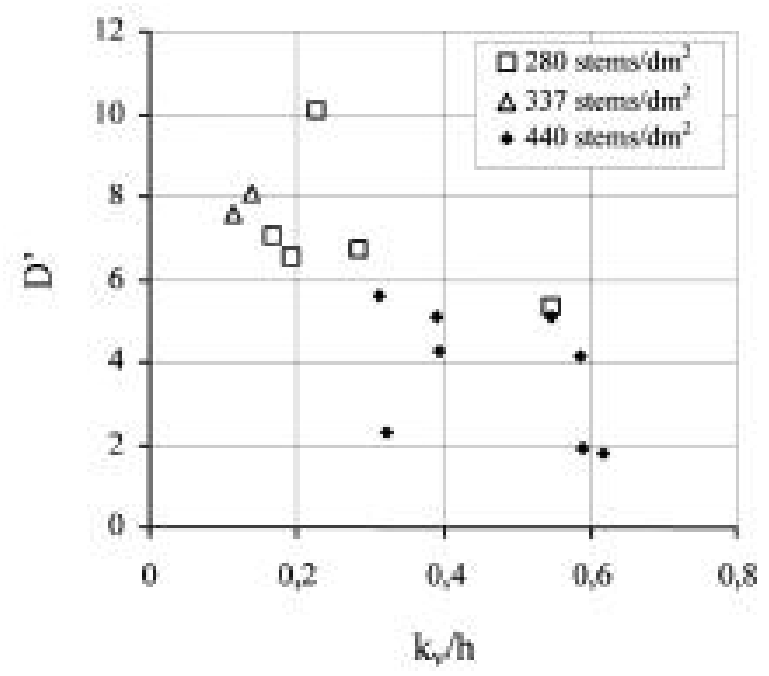

Fig. 9 - Values of $D^{\prime}$ parameter corresponding to different stem concentration and relative roughness values. 

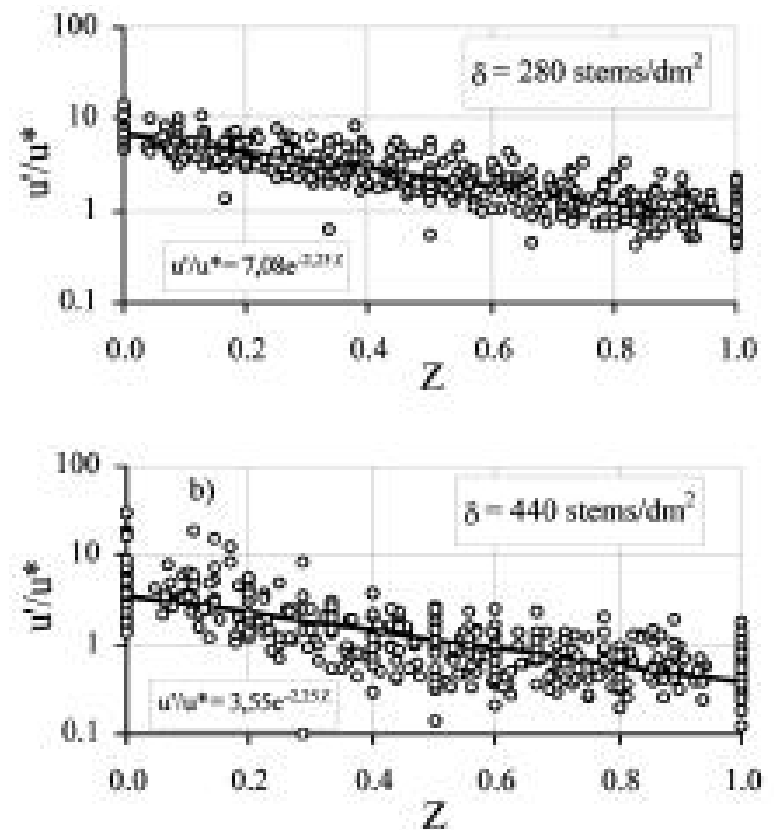

Fig. 10 - Fitting of eq. (5) to experimental turbulence intensity distributions characterized by a given value of the stem concentration.

Figure 10 shows that the turbulence intensity tends to damp for increasing stem concentration values. This behavior agrees with previous turbulence measurements carried out in gravel bed channels [14, 37], showing that turbulence intensity decreases for increasing bed roughness values.

In conclusion, the developed analysis showed that eq. (5) is applicable in the zone $Y_{t} \leq Y \leq Y_{\max }$, and turbulence intensity is damped for increasing values of the stem concentration (the scale factor $D^{\prime}$ decreases from 7.84 to 3.55 when $\delta$ increases from 337 to 440 stems $/ \mathrm{dm}^{2}$ ).

Damping of turbulence intensity can be explained taking into account that when $\delta$ increases the momentum exchange between the vegetation layer and the zone above the vegetation drastically diminuishes [15]. In other words, when the stem concentration increases, the intrusion of low velocity flow paths from the vegetation layer $\left(0 \leq Y \leq Y_{t}\right)$ to the zone above the vegetation $\left(Y_{t} \leq Y \leq Y_{\max }\right)$ is limited and, as a consequence, for $Y \geq$ $Y_{\max }$ the local velocity variability reduces.

\subsection{The relative turbulence intensity distribution}

The experimental turbulence intensity profile can also be analyzed using the ratio $u^{\prime} / U$ named relative turbulence intensity $[4,19,28]$.

Excluding a zone very near the bed $(Y<0.003$ for the smooth bed) in which viscous effects are dominant, Blinco and Partheniades [4] showed that for a given roughness condition the relative turbulence intensity decreases with the relative depth. Increasing of roughness (from smooth to rough bed) produces an increase of the relative turbulence intensity values.

As an example, Figure 11 shows the pairs $\left(Y, u^{\prime} / U\right)$ corresponding to four experimental runs. Along the relative turbulence intensity profiles three regions, marked by two relative water depths $Y_{1}<Y_{\mathrm{t}}$ and $Y_{2}>Y_{\mathrm{t}}$, can be identified:

1) for $Y_{1}^{\prime}<Y<Y_{2}^{\prime}$ (black dots in Fig. 11) the relative turbulence intensity exponentially decreases with the distance from the bed;

2) for $Y<Y_{1}$ (white dots in Fig. 11), i.e. for water depth close to the bed, both the flow velocities and the turbulence intensity values are very small and their ratio can increase or decrease with the bottom distance depending on which variable ( $U$ or $u$ ') is prevalent;

3) for $Y>Y_{2}$ (white dots in Fig. 11) the variability of the relative turbulence intensity is not appreciable and for $Y>Y_{\max } u^{\prime} / U$ takes a constant value.

This behavior of the relative turbulence intensity can be explained analyzing both the instantaneous turbulence distribution and the flow velocity profile. In fact, the experimental runs showed that for $Y>Y_{2}^{\prime}$ the measured values of both the turbulence intensity $u$ ' and the local flow velocity $U$ are quasi-constant and that those values become constant for $Y \geq Y_{\max }$.

In the range $Y_{1}^{\prime}<Y<Y_{2}^{\prime}$ two different trends of $u^{\prime}$ and $U$ with $Y$ determine the same exponential-type trend of the relative turbulence intensity profile: for $Y_{t}<Y<Y_{2}^{\prime}$ both the decrease in $u^{\prime}$ and the increase in $U$ with $Y$ determine a decreasing ratio $u^{\prime} / U$; for $Y_{1}^{\prime}<Y<Y_{t}$ both $u^{\prime}$ and $U$ increase with $Y$ but the ratio $u^{\prime} / U$ follows the same exponential trend established in the range $Y_{t}<Y<Y_{2}^{\prime}$.

Thus, in contrast to the turbulence intensity distribution $u^{\prime} / u^{*}$, no angular discontinuity can be observed at the top of the vegetation layer, i.e. at $Y=Y_{t}$.

The behavior of the relative turbulence intensity profile observed in the range $Y_{1}<Y<Y_{2}$ is very similar to that observed by Blinco and Partheniades [4],
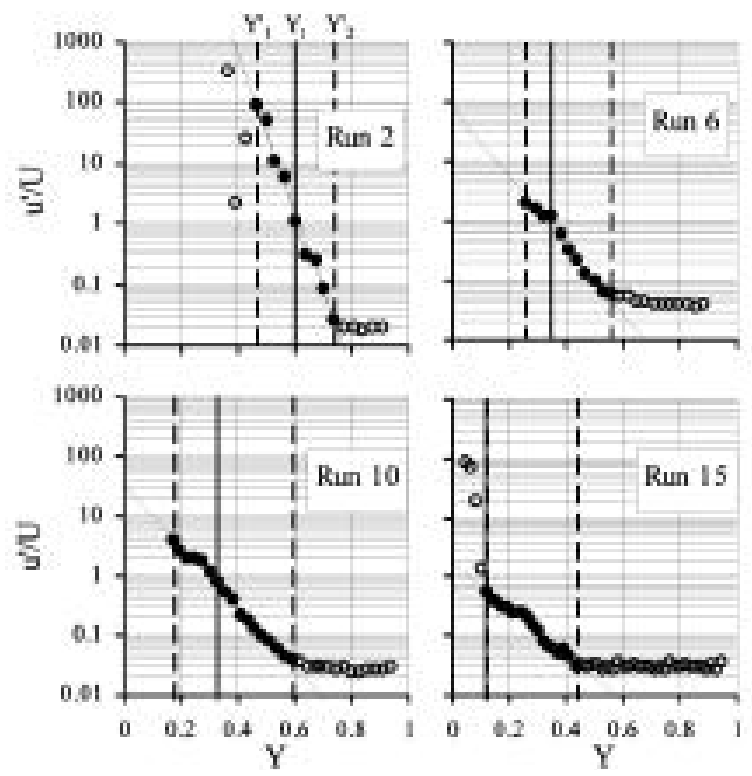

Fig. 11 - Relative turbulence intensity profiles measured in four experimental runs. 


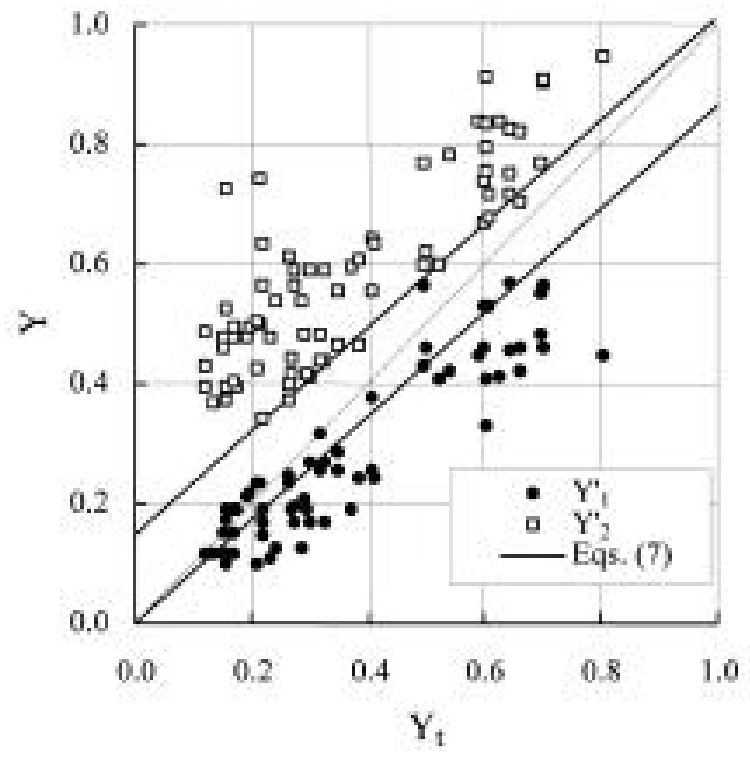

Fig. 12 - Relationship between the relative water depth $Y_{1}^{\prime}$ and $Y_{2}^{\prime}$ and the relative water depth $Y_{t}$ at which the maximum turbulence intensity occurs.

who found a decrease in $u^{\prime} / U$ above the viscous sublayer both in smooth and in rough bed.

The analysis of all measured relative turbulence intensity profiles showed that at $Y=Y_{t}$ the relative intensity $u^{\prime} / U$ assumes values ranging from 0.3 to 1 ; when $Y=Y_{2}^{\prime}$ the value of $u^{\prime} / U$ ranges from 0.02 to 0.06 . These extreme values are very similar to those observed by Blinco and Partheniades [4] near the bed $\left(u^{\prime} / U=0.4-0.6\right)$ and near the free surface $\left(u^{\prime} / U=\right.$ 0.05 ). Close to the bed (for $Y<Y_{1}$ ) the relative turbulence intensity $u^{\prime} / U$ moves away from the exponential decreasing trend; this result can be justified, according to Blinco and Partheniades [4], taking into account that the viscous effects become dominant.

In Figure 12 the relative depths $Y_{1}^{\prime}$ and $Y_{2}^{\prime}$ are plotted versus $Y_{t}$, assumed, as aforesaid, as a measure of the relative local bent vegetation height. The relative depth values $Y_{2}$ fall beyond the bisector line while the relative depths $Y_{1}$ fall below this line. This result confirms that the top of the vegetation layer falls inside the region $Y_{1}^{\prime} \leq Y \leq Y_{2}^{\prime}$. According to Figure 12, the values of the relative depths $Y_{1}^{\prime}$ and $Y_{2}^{\prime}$ increase with the relative roughness $k_{v} / h$, so that when $k_{v}=0$, i.e. without bed vegetation, $Y_{1}^{\prime}=0$ and the reference plane coincides with the bed; if the vegetation becomes emergent it means that $k_{v} / h=1$ and, thus, $Y_{2}=1$.

The relative depths $Y_{1}$ and $Y_{2}$ defining the three zones of the velocity profile (Figure 1), estimated using the following equations (7) [6], are also reported in Figure 12:

$$
\begin{gathered}
Y_{1}=0.865 Y_{t}, \\
Y_{2}=0.15+0.865 Y_{t} .
\end{gathered}
$$

Figure 12 clearly demonstrates that $Y_{1} \leq Y_{1}$ and $Y_{2}^{\prime} \geq Y_{2}$; in other words the region $Y_{1}^{\prime} \leq Y \leq Y_{2}^{\prime}$ of the relative turbulence intensity profile, contains the zone II of the velocity profile (Figure 1$)$. Some pairs $\left(Y_{t}\right.$,
$\left.Y_{1}\right)$ are located above the straight line plotting eq. (7a); this circumstance can be justified taking into account that eq. (7a) is not theoretically deduced. In fact, eq. (7a) was obtained applying the least squares method to pairs $\left(Y_{\mathrm{t}}, Y_{1}\right)$ deduced by measured velocity and turbulence intensity profile.

The values of $Y_{2}$ have been also compared with the relative water depth $Y_{\max }$; Figure 13 shows that the pairs $\left(Y_{\max }, Y_{2}\right)$ approach the bisector line and $Y_{2}^{\prime} \leq Y_{\max }$

Taking into account these last results and eq. (6), the following normalized variable was introduced:

$$
Z_{t}=\frac{Y-Y_{t}}{Y_{2}^{\prime}-Y_{t}}
$$

Using the normalized variable $Z_{t}$ the following exponential turbulence intensity distribution is proposed:

$$
\frac{u^{\prime}}{U}=A \exp \left(-B Z_{t}\right)
$$

in which $A$ and $B$ are constants to be estimated by measurements.

For $Z_{\mathrm{t}}=1$ the measured turbulence intensity profiles show $u^{\prime} / U$ values ranging from 0.02 to 0.06 . For $Z_{\mathrm{t}}=0$ the variable $u^{\prime} / U$ is equal to $A$ and falls in the range $0.3-1.0$, which can be considered very narrow taking into account that the $u^{\prime} / U$ values vary from 0.02 to 1000 . These boundary conditions $\left(u^{\prime} / U\right.$ values for $Z_{\mathrm{t}}=0$ and $Z_{\mathrm{t}}=1$ ) completely define equation (9). In other words, the two boundary conditions allow us to identify the numerical values of $A$ and $B$.

Neglecting these boundary conditions, for each experimental run the constants $A$ and $B$ were estimated by the least squares method using all experimental data collected in the measurement cross-section. As an example, Figure 14 shows the arrangement of eq. (9)

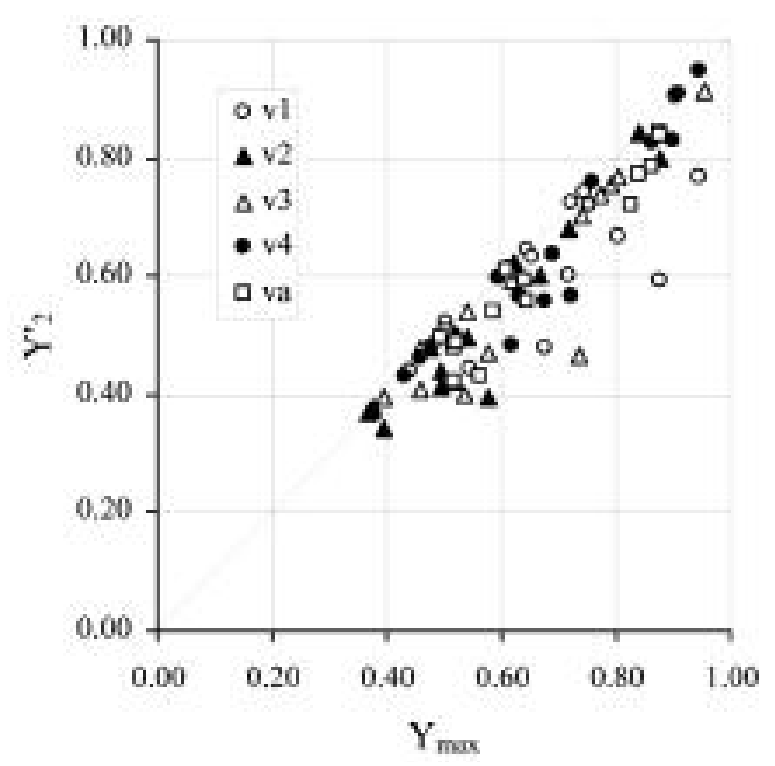

Fig. 13 - Relationship between $Y_{2}^{\prime}$ and the relative water depth $Y_{\max }$ at which the maximum velocity occurs. 

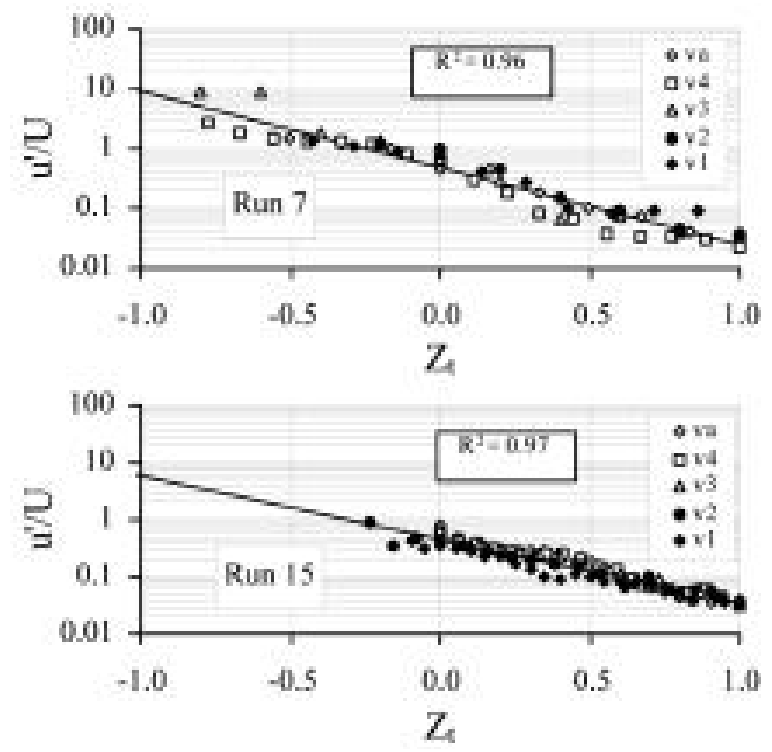

Fig. 14 - Fitting of eq. (9) to the relative turbulence intensity profiles measured in two experimental runs.

to the experimental pairs $\left(Z_{t}, u^{\prime} / U\right)$ for runs 7 and 15 . The estimated parameters $A$ and $B$ are plotted versus the relative roughness $k_{v} / h$, for each vegetation concentration, in Figure 15. This figure confirms that the $A$ and $B$ parameters do not change significantly with either the relative roughness or stem concentration; in other words $A$ and $B$ can be assumed constant, as established by the boundary conditions, and equal to 0.49 and 2.64, respectively. As an example for runs 7 and 15 , Figure 16 shows the fitting of the theoretical distribution (9) with parameters $A$ and $B$, respectively, equal to 0.49 and 2.64 .

In conclusion, eq. (9) with $A=0.49$ and $B=2.64$ allows us to describe the relative turbulence intensity distribution for any vegetation concentration. Further experimental runs should be carried out in order to confirm these results and to test the invariance of the parameters $A$ and $B$.

\section{Conclusions}

In this paper the characteristics of the longitudinal turbulence intensity distribution of an open channel flow over a flexible grass vegetation was investigated by local flow velocity measurements carried out by a 2D Acoustic Doppler Velocimeter.

The analysis of the measured turbulence intensity distributions showed that the peak value is located at the same relative water depth where the velocity distribution shows an inflection point and the vertical velocity gradient reach the maximum value. Approaching to the free surface the vertical velocity gradient decreases and the turbulence intensity decreases. At a relative water depth $Y_{\max }$ where the flow velocity assumes a constant value, the vertical velocity gradient reaches very small values.
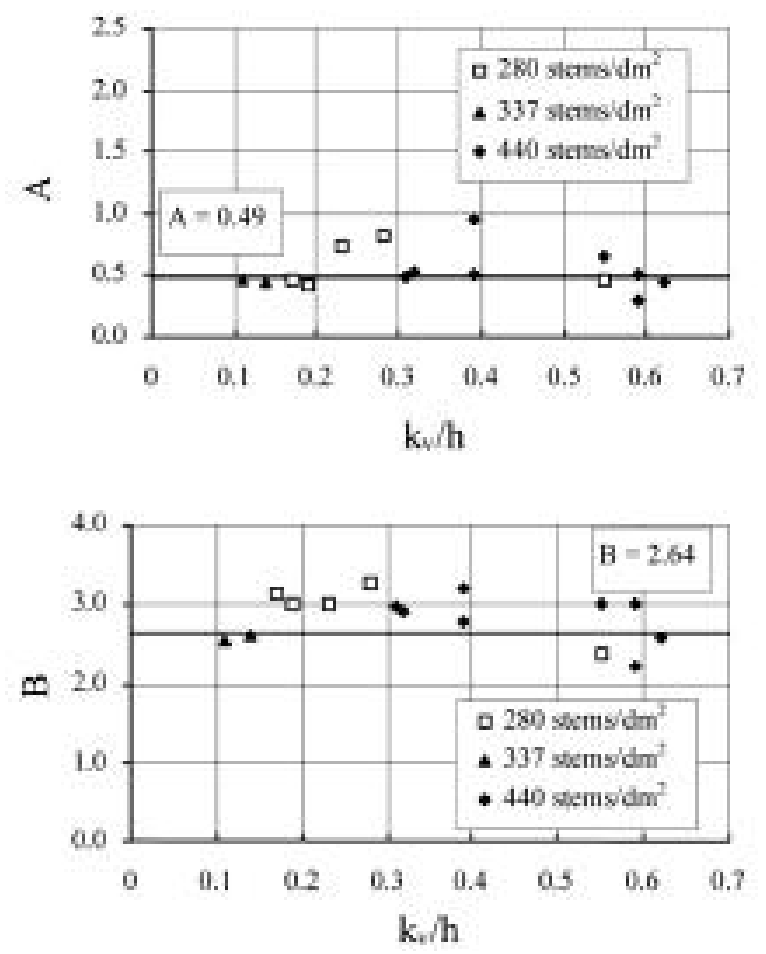

Fig. $\quad 15 \quad$ - Values of $A$ and $B$ parameters corresponding to different stem concentration and relative roughness values.
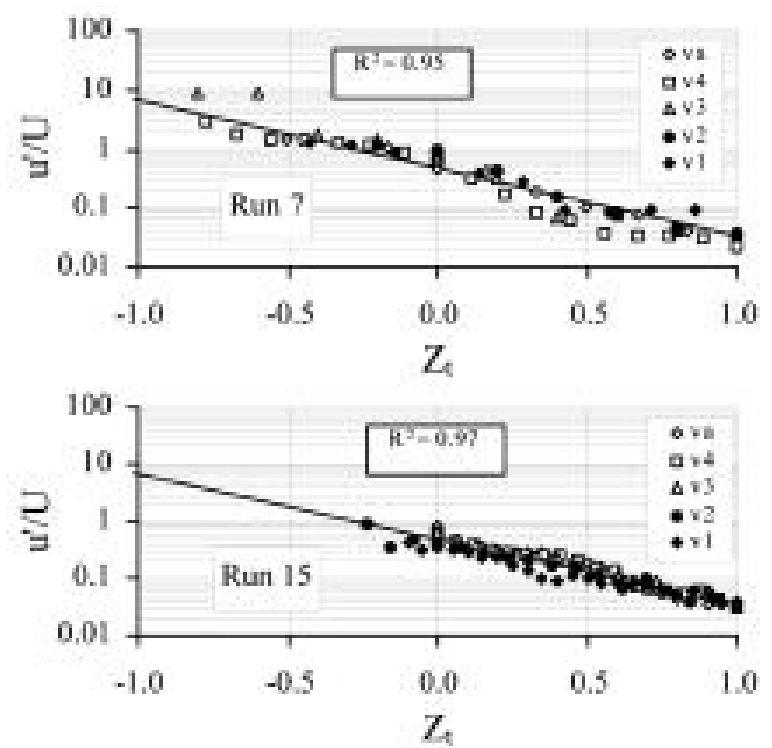

Fig. 16 - Fitting of eq. (9) with $A=0.49$ and $B=2.64$ to the relative turbulence intensity profiles measured in two experimental runs.

The analysis also showed that the peak value of the turbulence intensity profile is strongly influenced by the vegetation roughness. Since the relative depth $Y_{t}$, at which the maximum turbulence intensity is located, increases for increasing relative roughness values the whole turbulence intensity profile is shifted towards the free surface.

Since the normalized turbulence intensity profiles showed in the range $Y_{\mathrm{t}}<Y<Y_{\max }$ a decreasing trend similar to that observed in non-vegetated beds, an exponential law, similar to Nezu's law, including two 
parameters $\left(\lambda^{\prime}, D^{\prime}\right)$ was initially adopted. The analysis showed that the parameter $l$ ' has a low variability with both the stem concentration and the relative roughness; therefore a constant value of $\lambda^{\prime}$, equal to 2.25 , can be used.

The turbulence intensity analysis confirmed the applicability of the profile (5) with $\lambda^{\prime}=2.25$ and a scale factor $D^{\prime}$ decreasing for increasing values of the stem concentration. In other words, the analysis confirmed that for increasing stem concentration the turbulence intensity is damped, because the momentum exchange between the vegetation layer and the zone above the vegetation drastically reduces.

The measurements also allowed us to study the relative turbulence intensity profiles and three regions, marked by two relative water depths $Y_{1}^{\prime}$ and $Y_{2}^{\prime}$, were defined. In particular, for relative water depths $Y$ less than $Y_{2}^{\prime}$ and greater than $Y_{1}^{\prime}$ the relative turbulence intensity exponentially decreases with the distance from the bed, according to eq.(9). A new two-parameter exponential distribution describing the relative turbulence intensity $\left(u^{\prime} / U\right)$ was proposed. Fitting of this distribution to all available experimental profiles showed that the parameters $A$ and $B$ can be assumed constant and their numerical value $(A=0.49$ and $B=2.64$ ) can be calculated applying two known boundary conditions. Furthermore, the other two unknown parameters of the exponential relative turbulence intensity distribution are equal to $Y_{\mathrm{t}}$ and $Y_{\max }$ and, as a consequence, have a clear physical meaning.

Further experimental runs should be carried out in order to confirm these results and to test the invariance of the parameters $A$ and $B$.

\section{References}

[1] AfZalimeher H., Anctil F., Accelerating shear velocity in gravel-bed channels, Journal of Hydrological Sciences (2000) 45 (1), 113-124.

[2] BAYAZIT M., Free surface flow in a channel of large relative roughness, Journal of Hydraulic Research (1976), 14, 115-126.

[3] Barko J., GunNison D., CARPenter S., Sediment interactions with submerged macrophyte growth and community dynamics, Acquatic Bot. (1991) 41, 4165.

[4] Blinco P.H., Partheniades E., Turbulence characteristics in free surface flows over smooth and rough boundaries, Journal of Hydraulic Research (1971), 9, 43-69.

[5] Cantwell B.J., Organized motion in turbulent flow, Ann. Rev. Fluid Mech. (1981) 13, 457-515.

[6] Carollo F.G., Ferro V., Termini D., Flow velocity measurement in vegetated channels, Journal of Hydraulic Engineering (2002) 128 (7), 664-673.

[7] CLARK J.A., A study of incompressible turbulent boundary layers in channel flows, Proceedings of ASME, Journal of Basic Engineering (1968), 455-468.

[8] DixON K., Florian J., Modeling mobility and effect of contaminants in wetlands, Environ. Toxicology Chem. (1993) 12, 2281-2292.
[9] Ghisalberti M., NePF H.M., Mixing layer and coherent structures in vegetated acquatic flows, Journal of Geophysical Reseach (2002) 107 (2).

[10] Gourlay M.R., Discussion of 'Flow resistance in vegetated channels' by N. Kouwen, T. E. Unny and $H$. M. Hill, Proceedings of ASCE, Journal of Irrigation and Drainage Division (1970) 96 (3), 351-357.

[11] GRASS A.J., Structural features of turbulent flow over smooth and rough boundaries, Journal of Fluid Mechanics (1971) 50, 233-255.

[12] Ikeda S., Kanazawa M., Three dimensional organized vortices above flexible water plants, Journal of Hydraulic Engineering (1996) 122 (11), 634-640.

[13] JACKSOn R., Sedimentological and fluid-dynamic implications of the turbulent bursting phenomenon in geophysical flows, Journal of Fluid Mechanics (1976) 77 (part 3), 531-560.

[14] KIRONOTO B.A., GraF W.H., Turbulence characteristics in rough uniform open-channel flow, Proc., Institute Civil Engineering (1995) 112 (Part 2), 336-348.

[15] Kouwen N., LI R.M., Biomechanics of vegetated channel linings, Proceedings of ASCE, Journal of Hydraulics Division (1980) 106 (6), 1085-1103.

[16] Kouwen N., Unny E., HiLl H.M., Flow retardance in vegetated channels, Proceedings of ASCE, Journal of Irrigation and Drainage Division (1969) 95 (2), 329-342.

[17] Kraus N.C., Lohrmann A., Cabrera R., New acoustic meter for measuring $3 D$ laboratory flows, Proceedings of ASCE, Journal of Hydraulic Engineering (1994) 120 (3), 406-412.

[18] Kutiua V., Hong H.T.M., A numerical model for assessing the additional resistance to flow introduced by flexible vegetation, Journal of Hydraulic Research (1996) 34 (1), 99-114.

[19] LAUFER J., Investigation of turbulent flow in a two dimensional channel, National Advisory Committee for Aeronautics NACA (1951), Tech. Report 1053.

[20] Lemmin U., Rolland T., Acoustic Velocity profiler for laboratory and Field Studies, Proceedings of ASCE, Journal of Hydraulic Engineering (1997) 123 (12), 1089-1097.

[21] LÓPEZ F., GARCía M., Open channel flow through simulated vegetation: suspended sediment transport modelling, Water Resourches Research (1998) 34 (9), 2341-2352.

[22] McQuiveY R.S., RichardSON E.V., Some turbulence measurements in open channel flow, Proceedings of ASCE, Journal of Hydraulics Division (1969) 95 (1), 209-223.

[23] Nakagawa H., Nezu I., Prediction of the contributions to the Reynolds stress from the bursting events in open-channel flows, Journal of Fluid Mechanics (1977) 80, 99-128.

[24] NePF H.M., Drag, turbulence, and diffusion in flow through emergent vegetation, Water Resources Research (1999) 35 (2), 479-489.

[25] Nepf H.M., Vivoni E.R., Flow structure in depthlimited, vegetated flow, Journal of Geophysical Reseach (2000) 105 (12), 28547-28557.

[26] NEZU I., Turbulence intensities in open-channel flows, Proc. of Japan Soc. Civil Engrs (1977) 261, 67-76.

[27] Nezu I., Rodi W., Open-channel flow measurements with a Laser Doppler Anemometer, Proceedings of ASCE, Journal of Hydraulic Engineering (1986) 112 (5), 335-355. 
[28] Nezu I., Nakagawa H., Turbulence in open-channel flows. (1993), A.A. Balkema Publishers, Rotterdam, the Netherlands.

[29] NORTEK AS., ADV Operation Material. January 2, (1996).

[30] PhILliPs J., Fluvial sediment storage in wetlands; Water Res. Bull. (1989) 25, 867-872.

[31] RAUPACH M.R., Conditional statistics of Reynolds stress in rough-wall and smooth-wall turbulent boundary layers, Journal of Fluid Mechanics (1981) 108, 363-382.

[32] Shvidchenko A.B., Pender G., Macroturbulent structure of open-channel flow over gravel beds, Water Resources Research (2001) 37 (3), 709-719.

[33] Smutek R., Discussion of 'Measurement of Turbulence in Water' by E.V. Richardson and R.S. McQuivey, Proceedings of ASCE, Journal of the Hydraulic Division (1969) 95 (1), 519-523.

[34] Steffler P.M., Rajaratnam N., Peterson A.W., LDA Measurements of mean velocity and turbulence distribution in a smooth rectangulary open channel, Water Resources Engineering (1983), Report 83-4, Dept. of Civil Eng., Univ. of Alberta, Canada.

[35] Tsujimoto T., Kitamura T., Velocity profile of flow in vegetated-bed channels, KHL Progressive Report (1990), Hydraulic Laboratory, Kanazawa University.

[36] WaHL T.L., Analyzing ADV data using WinADV, ASCE Joint Conference on Water Resources Engineering and Water Resources Planning \& Management (2000) Minneapolis July 30 - August 2, USA, 10 pp.

[37] Wang J., Dong Z., Chen C., Xia Z., The effects of bed roughness on the distribution of turbulent intensities in open channel flow, Journal of Hydraulic Research (1993) 31 (1), 89-98.

\section{SUMMARY}

Vegetation altering hydrodynamic conditions of an open channel flow controls the exchanges of sediment, nutrients and contaminants. In this paper the turbulence structure of open-channel flow over a flexible grass vegetation is investigated. Velocity measurements were carried out, in a rectangular flume, using a 2D-ADV (Acoustic Doppler Velocimeter) for different values of stem concentration, water discharge, and bed slope. The experimental results showed that: 1) the maximum value of the longitudinal turbulence intensity occurs at a water depth close to the bent vegetation height; 2) the turbulence intensity damps for increasing values of the stem concentration; 3) above the vegetation height, an exponential distribution, similar to Nezu's law, can be fitted to the measured longitudinal turbulence intensity profile.

Finally, a new relative turbulence intensity distribution is proposed and fitted to the measured profiles. This relative turbulence intensity distribution needs the estimate of two parameters coinciding with the vegetation height and the water depth at which the maximum flow velocity occurs.

\section{Key words:}

Vegetated channels, Flexible vegetation, Acoustic Doppler Velocimeter, Turbulence intensity, Relative turbulence intensity.

\section{Symbols}

$A, B=$ coefficients of eq. (9)

$b_{0}, b_{1}=$ coefficients of eq. (3)

$D^{\prime}=$ coefficient of eq. (1)

$D^{\prime}=$ coefficient of eq. (5)

f.a.i. $=$ frontal area index

$h=$ flow depth

$H_{v}=$ vegetation height in absence of flow

$k=$ von Karman's constant

$k_{s} \quad=$ equivalent bed roughness height

$k_{s}^{{ }^{+}}=$shear Reynolds number

$k_{y}=$ vegetation height in presence of flow

$N=$ number of samplings for the measurement of local velocity

$Q=$ water discharge

$s \quad=$ flume slope

$U=$ local mean velocity

$u^{*}=$ shear velocity

$u^{\prime}=$ longitudinal turbulence intensity

$u_{\text {max }}^{\prime}=$ maximum longitudinal turbulence intensity

$u_{i}=$ instantaneous longitudinal velocity

$y=$ distance from channel bed

$y^{+}=$distance from channel bed scaled to $n / u^{*}$

$Y=$ relative depth, $y / h$

$Y_{1}=$ relative depth bounding zone I of velocity profile

$Y_{2}=$ relative depth bounding zone II of velocity profile

$Y_{1}=$ relative depth bounding the bottom region of relative turbulence profile

$Y_{2}^{\prime}=$ relative depth bounding intermediate region of relative turbulence profile

$Y_{f}=$ relative depth at which the inflection on velocity profile is located

$Y_{\max }=$ relative depth at which maximum longitudinal velocity is located

$Y_{t}=$ relative depth at which maximum turbulence intensity is located

$Z \quad=$ dimensionless distance from bed defined by eq. (6)

$Z_{t} \quad=$ dimensionless distance from bed defined by

eq. (8)

$\delta=$ number of stems per unit area

$\theta=$ momentum thickness

$\lambda=$ coefficient of eq. (1)

$\lambda^{\prime}=$ coefficient of eq. (5)

$v=$ kinematic viscosity 
CONFERENCES

$16^{\text {th }}$ International ISTVS Conference, Turin, Italy, November 25-28 2008

According to the aims of the International Society for Terrain-Vehicles System (www.istvs.org), the Conference will cover all the aspects of interaction and mobility of vehicles with the terrain, as well as the tradictional and new applications. The main following topics represent an outline and not a limit for people having interest to submit paper and/or attend at the Conference:

* Terramechanics, geomechatronics

* Vehicles mobility and safety

* Vehicle performance assessment

* Agricultural, construction and operating machines

* Planetary rover, mobil robotics and autonomous navigation

* Components and systems concurrent simulation

* Mobility of people with disabilities

The Conference is organized by IMAMOTER, Institute of the National Research Council, seat of ISTV's European Secretary, in Turin, that saw the ISTV's birth in 1061.

XXXIII CIOSTA - CIGR V Conference 2009

Tecnology and management to ensure sustinable agriculture, agro-systems, forestry and safety 17-19 June 2009, Italy - Reggio Calabria

DISTAFA - Università Mediterranea di Reggio Calabria 